\title{
Go deep! Benefits of a deep freeze during distal aortic repair
}

\author{
Joseph S. Coselli, MD
}

\footnotetext{
From the Division of Cardiothoracic Surgery, Michael E. DeBakey Department of Surgery, Baylor College of Medicine; the Section of Adult Cardiac Surgery, Department of Cardiovascular Surgery, Texas Heart Institute; and CHI St. Luke's Health-Baylor St. Luke's Medical Center, Houston, Tex.

Disclosures: Author has nothing to disclose with regard to commercial support.

Received for publication March 14, 2017; accepted for publication March 17, 2017; available ahead of print April 14, 2017.

Address for reprints: Joseph S. Coselli, MD, One Baylor Plaza, BCM 390, Houston, TX 77030 (E-mail: jcoselli@ bcm.edu).

J Thorac Cardiovasc Surg 2017;154:387-8

$0022-5223 / \$ 36.00$

Copyright (c) 2017 by The American Association for Thoracic Surgery

http://dx.doi.org/10.1016/j.jtcvs.2017.03.062
}

The use of endovascular techniques to treat chronic distal aortic dissection of the thoracoabdominal aorta is being reported with increasing frequency. ${ }^{1,2}$ As of yet, there is no Food and Drug Administration-approved off-the-shelf device for thoracoabdominal aortic repair; nevertheless, significant progress is being made. Stent grafts with multiple branches that address both the true and false lumens of aortic dissection remain a technical and engineering challenge; these include scenarios in which none, one, or all of the visceral and renal arteries arise from either lumen. Until the endovascular technology becomes safe and established, the use of open techniques to repair chronic aortic dissection remains the standard of therapy.

Techniques for repair of the descending thoracic aorta and thoracoabdominal aorta have varied through the years and have included the "clamp and sew" approach, left heart bypass, and cardiopulmonary bypass with and without hypothermic circulatory arrest. In this issue of the Journal, Corvera and colleagues ${ }^{3}$ report on a large series of repairs performed during a 20-year period from 1995 to 2015. The patients were operated on through a left thoracotomy for repair of the aortic arch, descending thoracic aorta, and thoracoabdominal aorta. For this report, Corvera and colleagues $^{3}$ selected a cohort of 196 patients with chronic thoracoabdominal aortic dissections who underwent repair with deep hypothermia and circulatory arrest. Forty-four of the 196 underwent repair of the descending thoracic aorta only, with or without involvement of the arch, and the remainder had thoracoabdominal aortic aneurysms (TAAAs) repaired on the basis of the Crawford classification system. Corvera and colleagues ${ }^{3}$ are to be commended for their outstanding surgical skills and results. They report an overall operative mortality of $3.6 \%$ and a permanent stroke rate of $1 \%$. In addition, they observed spinal cord ischemia in 11 patients, with only $5(2.6 \%)$ of those patients having permanent paraplegia or paraparesis after the procedure. Acute renal failure occurred in $5.1 \%$, with hemodialysis necessary in $4.1 \%$. In this series, $2.6 \%$ of patients required tracheostomy and 10 patients $(5.1 \%)$

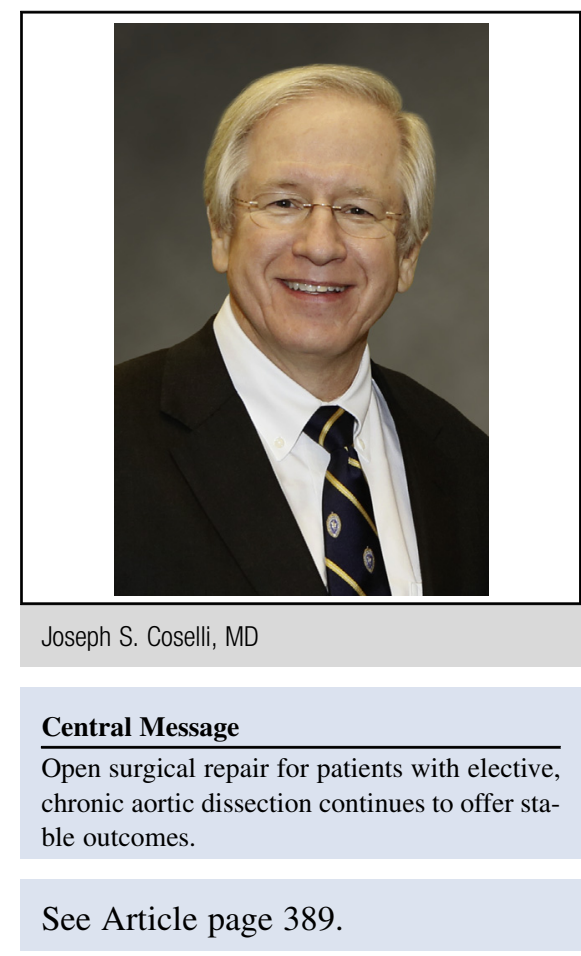

required reexploration for postoperative bleeding. Corvera and colleagues $^{3}$ convincingly showed the operative procedure to be durable, with late reintervention an uncommon occurrence. Two patients required reoperation for infected grafts, and anastomotic pseudoaneurysms occurred in only 6 patients $(3.1 \%)$. In addition, Corvera and colleagues ${ }^{3}$ reported a robust 10 -year survival of $60 \%$.

In open thoracoabdominal surgery, hypothermia is a valuable tool to provide organ protection and preservation. Corvera and colleagues $^{3}$ justifiably point out the disadvantages of this technique, which include but are not limited to parenchymal lung hemorrhage, longer perfusion times, and coagulopathy with postoperative bleeding. In addition to organ protection, a primary additional advantage of hypothermia is its capability of addressing pathology involving a part or the entirety of the transverse aortic arch. The results of Corvera and colleagues ${ }^{3}$ are indeed excellent within the context of a relatively young cohort of patients, with an average age of 58 years at the time of repair. Corvera and colleagues ${ }^{3}$ note that an important evolution in their technique was the addition of cerebrospinal fluid drainage in 2013.

In my own group's 30-year experience of TAAA repairs in 3309 patients, 857 patients had chronic aortic dissection and underwent elective repair; notably, almost half of these 
elective procedures were extensive repairs $(n=399$ extent II TAAA repairs). ${ }^{4}$ The 30 -day mortality in the overall group $(\mathrm{n}=857)$ was $5.0 \%$, the rate of renal failure requiring hemodialysis was $3.9 \%$, and the permanent paraplegia rate was $1.3 \%$. Similar to the series by Corvera and colleagues, ${ }^{3}$ the mean age in our series of elective repairs of chronic dissection was 56 years, which is a decade younger than most patients undergoing TAAA repair. This is a reflection of the fact that $27.3 \%$ of our patients had connective tissue disorder and $23.9 \%$ had Marfan syndrome, which is a considerably higher percentage than reported by Corvera and colleagues. ${ }^{3}$

We and others have reserved cardiopulmonary bypass with deep hypothermic circulatory arrest for patients with poor proximal aortic control for use when aortic clamping is anatomically not feasible because of either previous surgery, very large aortic diameter, or substantial arch involvement. We principally did not use cardiopulmonary bypass and hypothermic circulatory arrest in patients requiring extent III and extent IV repairs in our 857-patient chronic dissection cohort (there was a single exception in which circulatory arrest was used in a patient undergoing extent III repair). Although only 22 patients in the series of Corvera and colleagues ${ }^{3}$ series had Crawford extent III and extent IV aneurysms, their excellent results make a case for the use of this protective hypothermic modality even when dealing with these less-extensive TAAAs.

For the foreseeable future, patients with extensive TAAAs, particularly those with chronic aortic dissection, will be treated with open surgery at most institutions.
Certainly, with time improved branch technology, readily available off-the-shelf devices, and clinician expertise, endovascular TAAA repair will supplant and replace many, if not all, elective open TAAA procedures. The complexity of this pathology, however, particularly the need to incorporate the visceral and renal arteries, does not allow a rapid move from feasibility to widespread adoption of endovascular devices as the standard of care. Even when feasible, the durability of endovascular therapies will have to be proven for younger patients who typically have lower surgical risk, as well as for patients with connective tissue disorders such as Marfan syndrome and Loeys-Dietz syndrome.

In the interim, it is of great value for experienced highvolume, devoted aortic centers, such as that of Corvera and colleagues, ${ }^{3}$ to continue to validate the acceptable low morbidity, mortality, and durability of open repair in the treatment of this complex aortic pathology.

\section{References}

1. Kang WC, Greenberg RK, Mastracci TM, Eagleton MJ, Hernandez AV, Pujara AC, et al. Endovascular repair of complicated chronic distal aortic dissections: intermediate outcomes and complications. J Thorac Cardiovasc Surg. 2011; 142:1074-83.

2. Kitagawa A, Greenberg RK, Eagleton MJ, Mastracci TM, Roselli EE. Fenestrated and branched endovascular aortic repair for chronic type B aortic dissection with thoracoabdominal aneurysms. J Vasc Surg. 2013;58:625-34.

3. Corvera J, Copeland H, Blitzer D, Hicks A, Manghelli J, Hess P, et al. Open repair of chronic thoracic and thoracoabdominal aortic dissection using deep hypothermia and circulatory arrest. J Thorac Cardiovasc Surg. 2017;154:389-95.

4. Coselli JS, LeMaire SA, Preventza O, de la Cruz KI, Cooley DA, Price MD, et al. Outcomes of 3309 thoracoabdominal aortic aneurysm repairs. J Thorac Cardiovasc Surg. 2016;151:1323-38. 